\title{
Goldmann-Favre syndrome
}

INSERM

\section{Source}

INSERM. (1999). Orphanet: an online rare disease and orphan drug data base. GoldmannFavre syndrome. ORPHA:53540

Goldmann-Favre syndrome (GFS) is a vitreoretinal dystrophy characterized by early onset of night blindness, reduced bilateral visual acuity, and typical fundus findings (progressive pigmentary deg enerative changes, macular edema, retinoschisis). 